Savary.-Mémoires du Duc de Rovigo écrits de sa main. Paris et Londres, 1828, Vol. I, pp. 71-73.

Seetzen, Ulrich Jasper.-Reisen, etc. Edited by Kruse and others. Berlin, 18541859,4 vols.

Stoeber, Victor.-Manuel pratique de l'ophtalmologie. Paris et Strasbourg, 1834, p. 2. (R.S.M.) (278, f. 7.)

Vautier.-Topographie physique et médicale de Belbeys. In Desgenettes, Vol. II, p. 109 foll.

Vertray, Galli H.-Journal d'un officier de l'armée d'Égypte. Paris, 1883, p. 84.

Vetch, John.-An Account of the Ophthalmia which has appeared in England since the return of the British Army from Egypt. London, 1807. (K.S.M.) A practical Treatise on the Diseases of the Eye. London, 1820.

Walsh, Th.-Journal of the late Campaign in Egypt, etc. London, 1803.

Ware, James.-Remarks on the purulent Ophthalmia which has lately been epidemical in this Country. London, 1808. (R.S.M.) (Oph. 7. 78.)

Whyte, Douglas.-Mode of Managing Ocular Inflammation. In Med. and Phys. Journal, Vol. VIII (London, 1802), p. 209 foll.

Wilson, Robert Thomas.-History of the British Expedition to Egypt, etc. London, 1802 (1 vol.); 4th Edition, London, 1903 (2 vols.).

Wittman, William.-Travels in Turkey, Asia-Minor, Syria and across the Desert into Egypt, etc. London, 1803 (" On Ophthalmia," pp. 538-547).

Yates, William Holt,-The Modern History and Conditions of Egypt, etc. London, 1843, 2 vols.

Abbreviation: R.S.M.-Library of Royal Society of Medicine.

\title{
THE TREATMENT OF LIMBAL TUMOURS WITH RADIUM
}

BY

\section{T. HARRISON BUTLER}

BIRMINGHAM

THERE appears to be some doubt among ophthalmic surgeons regarding the effect of radium upon tumours of the limbus. The following cases may therefore be of some interest.

Mrs. A.C.-In this case there was a sessile tumour measuring about five millimetres in circumference at the limbus. There was a pedunculated portion about as large as the parent growth. The surface of the tumour was nodular, and the surrounding conjunctiva showed numerous enlarged vessels. Examination with the slitlamp and corneal microscope showed that there were sprays of growth spreading into the superficial part of the clear cornea, and in places reaching as far as the level of the margin of the pupil. Gallemaerts has described and figured such sprays in a case of limbal sarcoma. The tumour was considered on clinical grounds to be sarcomatous. The pedunculated part was removed and examined. It was found to be a haemangioma. The patient was treated at the Radium Institute, and after two applications the 
tumour disappeared. A drawing of the eye will be found in my Illustrated Guide to the Slit-Lamp, p. 41.

Miss E. M., aged 18 years.-First examined at the Birmingham Eye Hospital in November, 1919. There was a raised whitish mass on the temporal side of the left cornea and limbus. It was crescentic above and pyriform below. It measured $7.5 \mathrm{~mm}$. in its horizontal diameter and $3 \mathrm{~mm}$. vertically. About one quarter of the tumour covered the rim of the cornea. The tumour was surrounded by a purplish zone of dilated capillaries. The cornea was clear and vision unaffected. The patient said that the tumour had been growing "for some time." A diagnosis of limbal sarcoma was made, and the patient was sent to the Radium Institute.

On November 10,1919 , an eye spatula $8 \mathrm{~mm}$. square, containing 3.5 milligrammes of radium element was applied in actual contact with the growth, unscreened, for 45 minutes.

On December 3, 1919, the same treatment was applied for 45 minutes. The growth was now smaller, and the dilated capillaries less conspicuous.

The patient was treated again on January 2, 1920, on February 4, and on March 10. The same apparatus was used on each occasion, unscreened, but the exposure was now only 25 minutes. The growth steadily decreased after each irradiation.

April 14, 1920, a similar exposure was made of 20 minutes' duration. On May 28 there was scarcely any trace of the growth. A final exposure of 15 minutes' duration was given.

In April, 1926, the patient was again examined. There was no trace of any growth, but there were a few enlarged blood vessels in the region of the original tumour.

The patient, now married, was seen again in 1930 and was found to be completely cured.

Mrs. C. S., aged 57 years.-This patient was first seen in November, 1925, at the Birmingham Eye Hospital. A drawing of her eye will be found in An Illustrated Guide to the Slit-Lamp on Plate III, Fig. E (facing p. 62). There was at the temporal limbus of the right eye a roughly triangular area of brown pigmentation. The corneal microscope showed that in addition to the main mass obvious to the naked eye there was a wide-spread invasion of the conjunctiva and of the peripheral part of the cornea with dots and islets of pigment. These were situated in the anterior part of the cornea. The case was shown to the Ophthalmological Section of the Royal Society of Medicine, where it was examined by Mr. Treacher Collins and others. The opinion was unanimous that the condition was a melanotic malignant growth, most probably an epithelioma. The patient was sent to the Radium Institute and the following régime was carried out :-

November 13,1925 , treated with $5 \mathrm{mg}$. of unscreened radium for 
50 minutes. The effect of this irradiation was almost immediate. Under the corneal microscope migration of pigment was observed, and foci of brown pigment were changing to a murky yellow, and had a sclerosed appearance. The injection of the area affected was less marked. The main conjunctival mass had begun to shrink, and portions which raised the corneal surface were flattened down.

February 9, 1926. Very great improvement. The lower twothirds of the obvious growth has disappeared. There remains a pigmented nodule the size of a split-pea at the upper aspect. A similar exposure was given.

April 7, 1926. Treatment repeated. July 7, August 24, October 20 , similar treatment, but time reduced to 35 and 40 minutes.

November 25, 1926. Only a minute speck of pigment was visible to the naked eye. $3.5 \mathrm{mg}$. applied unscreened for 40 minutes.

February 21,1927 . The pigmentation is now visible only with a lens. The corneal microscope shows a general retrogression of the pigmentation, both in extent and intensity. Most of the islets have lost their brown colour and are yellowish and anaemic in appearance. Treated with $3.5 \mathrm{mg}$. for 30 minutes. September 27, 1927. Similar treatment. November 28. Similar treatment. February 1, 1928. Treated with $3.5 \mathrm{mg}$. for 30 minutes. Nothing can be seen with the naked eye. With the corneal microscope a few isolated spots of yellowish pigment can be seen.

January 24, 1929. A final application of $3.5 \mathrm{mg}$. for 20 minutes was given. Mrs. C. S. was seen again in September, 1931. With the slit-lamp a few isolated dots of pigment are visible here and there in the conjunctiva.

Mrs. C. S. was last seen on December 5, 1931. A careful examination with the slit-lamp showed a small collection of pigment dots in the region of the old tumour, forming a triangle. There were also some dots in the superficial part of the cornea, in the same situation that they originally occupied. There seemed to be more of them than there had been at the last examination, and so it was decided that a final radiation was necessary.

Miss R., aged 23 years. - This patient was first seen on March 2, 1928. She was referred to me by Mr. D. Priestley Smith. In the right eye there is an area of pigmentation in the conjunctiva close to the limbus, north-east of the cornea. This discoloration was first noticed a year ago, and the patient is quite sure that it is extending. Mr. Priestley Smith considered it to be a melanotic carcinoma, and I agreed with him. The patient was sent to the Radium Institute. On March 28, 1928, an irradiation was made for 30 minutes with $3.5 \mathrm{mg}$. of unscreened radium. May 3, 1928. The patch was decidedly smaller. The treatment was repeated. June 13, 1928. The pigmentation has almost disappeared. Treated 
with the same plate for 25 minutes. August 13, 1928. Treatment repeated for the last time. There is no sign of any pigmentation.

September 13, 1931. Three years after the first examination. A careful examination with the corneal microscope shows no trace of any pigmentation.

Mrs. N., aged 25 years. - I have unfortunately been unable to find my notes of this case, nor have I been able to see her again, as a letter was returned marked "gone away, no address." The following notes were made at the Radium Institute :-

November 11, 1927. A limbal tumour of the right eye was excised by Mr. Harrison Butler. It was examined and found to be haemangioma. The growth recurred. At date: there is a soft, non-ulcerated yellowish-pink growth on the inner half of the right eye. It is just beginning to creep over the adjacent part of the cornea. There is a considerable degree of sub-conjunctival haemorrhage at the outer part of the globe. Movement of the eye-ball is unaffected. The iris reacts normally. Vision not affected. Treated with $10 \mathrm{mg}$. of radium unscreened for 40 minutes.

December 19, 1927. Very little change in the appearance of the tumour, but patient says that it is paler in colour. Treated with the same strength for 40 minutes.

February 2, 1928. Slight but definite improvement. The growth is flatter, and paler, and there is less sub-conjunctival haemorrhage. March 31, 1928. Screen treatment tried. Radium plate 10 mgs. P.B. $1 / 10$ th $1 \frac{3}{4}$ hours. This caused a sharp reaction. June 7,1928 . A treatment with unscreened $10 \mathrm{mgs}$. for 54 minutes. After this the patient was lost sight of, but it is reasonable to suppose that had she not been cured she would have reappeared.

I have a recollection of another case of limbal sarcoma that was rapidly cured by radium treatment, but I cannot trace the notes.

These cases are the only examples of limbal tumour that $I$ have been able to collect from my practice during the past fifteen years. All have been treated with radium, and all have made a complete recovery. There may have been others but I have no recollection of them.

I have to thank the directors of the Radium Institute for the great interest they have taken in these cases and for furnishing me with the detailed notes of the methods employed. 